\title{
Determination of protodioscin in tribulus terrestris by reversed-phase high-performance liquid chromatography
}

\author{
Mikhail Sergeev ${ }^{1}$, Georgiy Zaitsev ${ }^{2}$, and Dmitry Yermolin ${ }^{1, *}$ \\ ${ }^{1}$ V.I. Vernadskiy Crimean Federal University, Prospekt Vernadskogo 4, Simferopol, Republic of \\ Crimea, Russia \\ ${ }^{2}$ Magarach All-Russia National Research Institute for Viticulture and Wine-Making, st. Kirov 31, \\ Yalta, Republic of Crimea, Russia
}

\begin{abstract}
In this study, high performance liquid chromatography (HPLC) was used to analyze the protodioscin content in Tribulus terrestris samples. They were separated by $\mathrm{C} 18$ chromatography column, gradient with $0.1 \%$ phosphoric acid solution and acetonitrile was used as the mobile phase with the flow rate of $0.5 \mathrm{~mL} / \mathrm{min}$, the column temperature was $45^{\circ} \mathrm{C}$, and the detection wavelength was $203 \mathrm{~nm}$. The results showed that the protodioscin content has a good linear correlation $(r>0.999)$ within the range of $50 \mathrm{mg} / \mathrm{L}$ to $1500 \mathrm{mg} / \mathrm{L}$. In samples of raw material from Crimea it was found: $0.546 \% \pm 0.013$ protodioscin and in analyzed material from Western Siberia it was $0.338 \% \pm 0.008$ for $n=3$. Raw materials of Tribulus terrestris growing in Crimea are more promising than similar raw materials from the West Siberian region due to the higher content of protodioscin for the production of biologically active products containing steroid saponins.
\end{abstract}

\section{Introduction}

Tribulus terrestris is an annual plant in the caltrop family (Zygophyllaceae). It grows in South Asia, Africa, Europe, northern Australia, Russian Federation (Crimean Republic, North Caucasus, Western and Eastern Siberia. Tribulus terrestris infusions, decoctions are widely used in alternative medicine in many countries. Bulgaria - erectile dysfunction treatment, Iran as a diuretic, laxative and syphilis treatment, India - radiculitis, in traditional Chinese medicine - eye diseases treatment [1]. In science-based medicine Tribulus terrestris extract is used as a booster for reproductive system. It is based on significant concentration of furostanol-type steroidal saponins in the plant represented by dioscin, protodioscin, tribestin, prototribestin, methylprototribestin, methylprotodioscin, pseudoprotodioscin, tribulosin, tribulusamide $\mathrm{C}$ and other compounds [2]. High concentrations of flavonoids, amino acids, lipids are also represented in Tribulus terrestris [3-6].

Protodioscin is a highliter to Tribulus terrestris extract quality control [7-9]. Preparations, containing furostanol glycosides are used to cardiovascular disease treatment [10].

\footnotetext{
*Corresponding author: dimayermolin@mail.ru
} 
On Figure 1, the biologically active compounds in Tribulus terrestris chemical structure is presented.

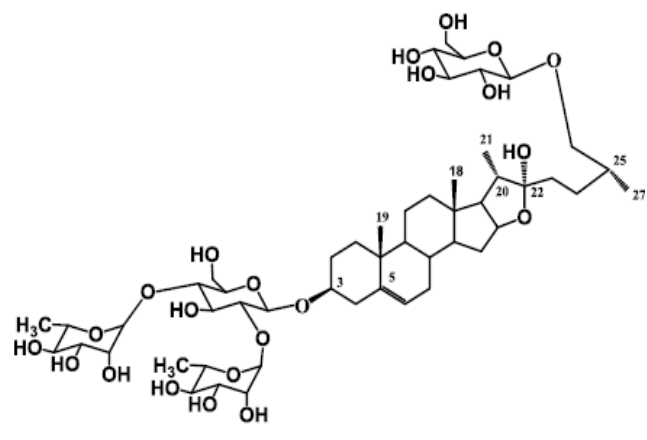

Protodioscin

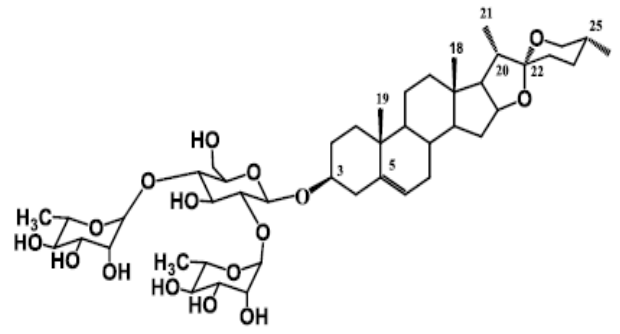

Dioscin

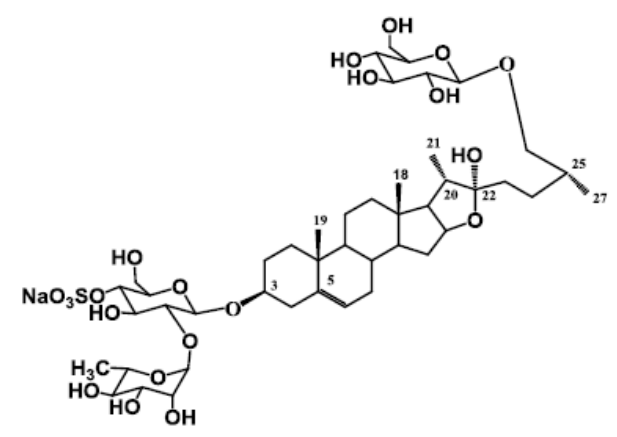

Prototribestin

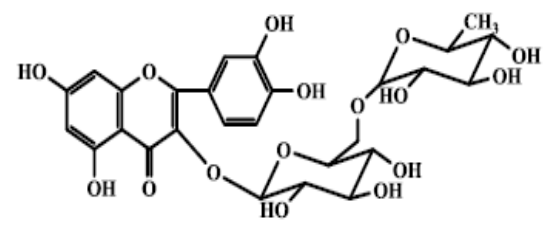

Rutin

Fig. 1. Structural formulae of the biologically active compounds in Tribulus terrestris.

Nutritional supplements with Tribulus terrestris extract are widespread among people involved in physical education and sport [11]. Plants bioactive substances helps to rise testosterone production. It is used as testosterone booster

Saponins bind to the hypothalamus receptors. The hypothalamus signals the start of luteinizing hormone production [12].

Studies was made by panel scientists headed by Kazys Milasius. It showed that Tribulus terrestris supplements usage significantly helps to double or triple testosterone level due to the 8-20 days course of administration [13]. The same study found that Tribulus terrestris consumption result certain increase of strenght and aerobics activities data within sportsmens.

There are sources that illustrating the need for additional research on the Tribulus terrestris bioactive substances impact upon sportsmen physical efficiency [14].

S.G. Angelova, Z. Gospodinova, M. Krasteva и G.G. Antov illustrates Tribulus terrestris cancer protection abilities. It was set that general bulgarian Tribulus terrestris extract has a pronounced dose-related and abscopal effect on breast cancellation viability. Saponin fraction has an increased inhibitory effect compared to the total extract. Apoptotic bodies are involved in Tribulus terrestris anticancer activity mechanisms. Structural changes and DNA fragmentation were observed as markers of early and late apoptosis in tumor cells after treatment [15].

The study is intended to define protodoiscin in Tribulus terrestris through reversedphase high-performance liquid chromatography. 


\section{Materials and methods}

\subsection{Materials}

Plant material. The study of the protodioscin content have been carried out with a plants, natively distributed in Crimea and Western Siberia. The aerial parts plants (leave, stem, fruit) were collected in September 2020 year.

Protodioscin standard was acquired in Sigma-Aldrich (G0299, CAS 55056-80-9). Acetonitrile was of HPLC grade and purchased from Lab-Scan (Poland).

\subsection{Sample Preparation}

Exactly 1.2 gram of the finely powdered plant material was extracted with $10 \mathrm{~mL}$ of $90 \%$ aqueous methanol by sonication within $60 \mathrm{~min}$. After one day of infusion, the extracts were centrifugation and filtered through a $0.2-\mu \mathrm{m}$ Iso-Disk Nylon filter (Supelco). Every sample solution was injected in triplicate.

\subsection{Calibration}

Standard compounds protodioscin (3 $\mathrm{mg}$ ) was dissolved in $2.00 \mathrm{~mL}$ of $50 \%$ aqueous methanol (stock solution); further calibration levels were prepared by diluting the stock solution with the same water/methanol mixture. The resulting range for the concentration of protodioscin was from 50 to $1500.0 \mathrm{mg} / \mathrm{L}$. All calibration levels were injected in triplicate, and the calibration data obtained $(\mathrm{R} 2=0.9999$ and $\mathrm{y}=1.379 \mathrm{X}+5.34)$ indicated linearity of the detector response in the range already mentioned.

Analytical Method. HPLC analysis was performed on a Agilent 1260 Infinity II LC system (equipped with a quaternary pump VL (G7111A), a vialsampler (G7129A), a multicolumn thermostat (G7116A), and a diode array detector VL (G1315D) from Agilent Technologies, Inc., Germany. A UCT Selectra AQUEOUS C18 column (150mm-2.1 mm, 5 $\mu \mathrm{m}$ particle size) from United Chemical Technologies (UCT) was used for all separations. The mobile phase, which consisted of water with of $0.1 \%$ phosphoric acid (A) and acetonitrile (B), was used for gradient elution from $90 \mathrm{~A} / 10 \mathrm{~B}$ to $100 \mathrm{~B}$ in $10 \mathrm{~min}$, then to $100 \mathrm{~B}$ in $2.5 \mathrm{~min}$. The flow rate was adjusted to $0.5 \mathrm{~mL} / \mathrm{min}$, the detection wavelength was $203 \mathrm{~nm}$, and $2 \mu \mathrm{L}$ of sample was injected. All separations were performed at $45^{\circ} \mathrm{C}$ temperature. Peaks were assigned by spiking the samples with standard compounds and comparing retention times.

\section{Results and discussions}

Despite the fact that protodioscin is not very well absorbed in the ultraviolet spectral range, thanks to the ethane nitrile (acetonitrile) as a mobile phase, and the use of an analytical column with a small diameter, it was possible to create an analytical technique with a completely acceptable level of sensitivity for protodioscin (the minimum detection level is about $10 \mathrm{mg} / \mathrm{L}$ at a signal to noise ratio of 3/1). Protodioscin concentration dependence at the peak area is linear, with a high correlation coefficient (0.99992) as is shown in Figure 2. 


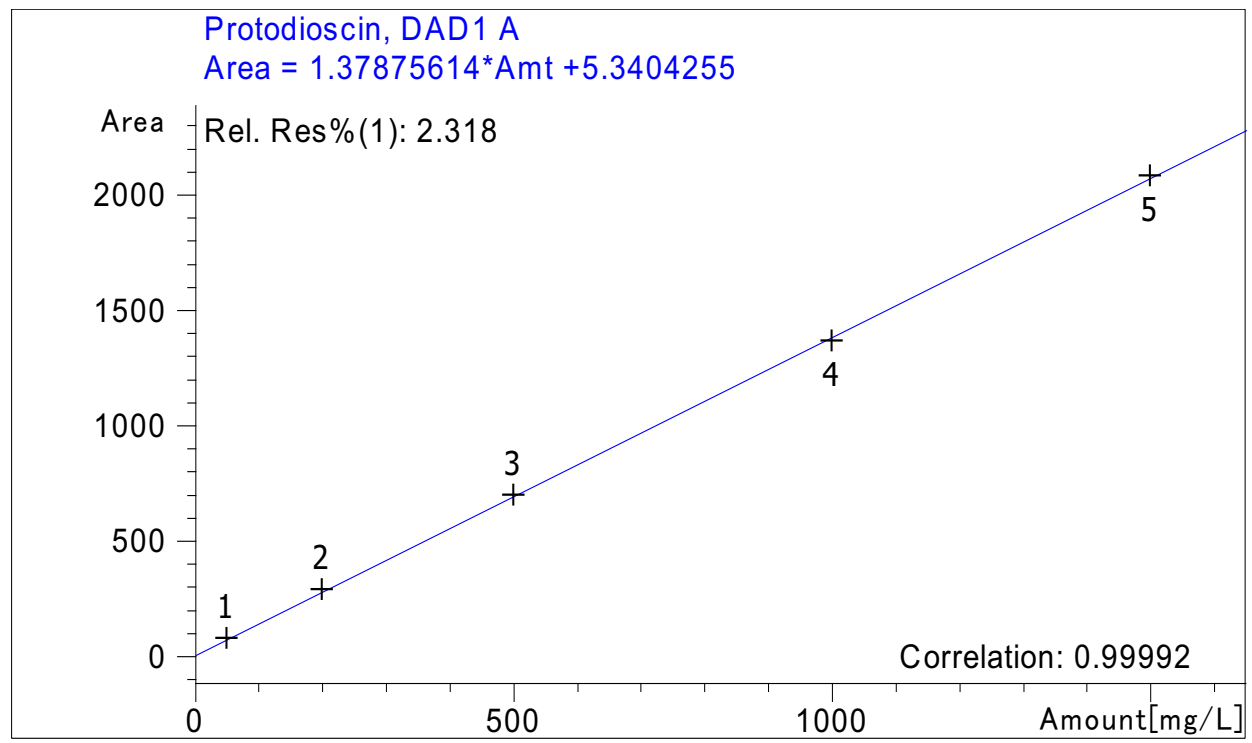

Fig. 2. Linearity test: Protodioscin concentration against the area of the chromatographic peak.

On Figure 3 and 4 There are represented raw materials chromatograms growing in the Republic of Crimea and Western Siberia.

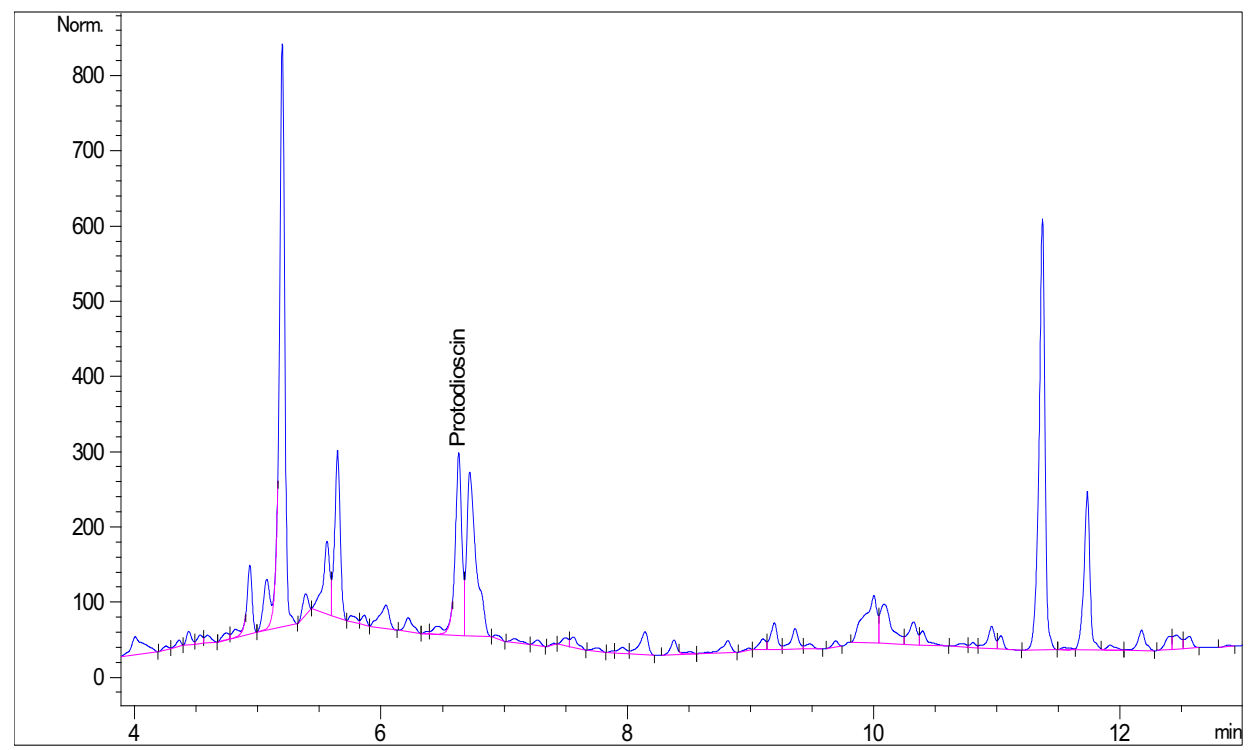

Fig. 3. Chromatogram of Tribulus. terrestris sample (aerial parts from Crimea). 


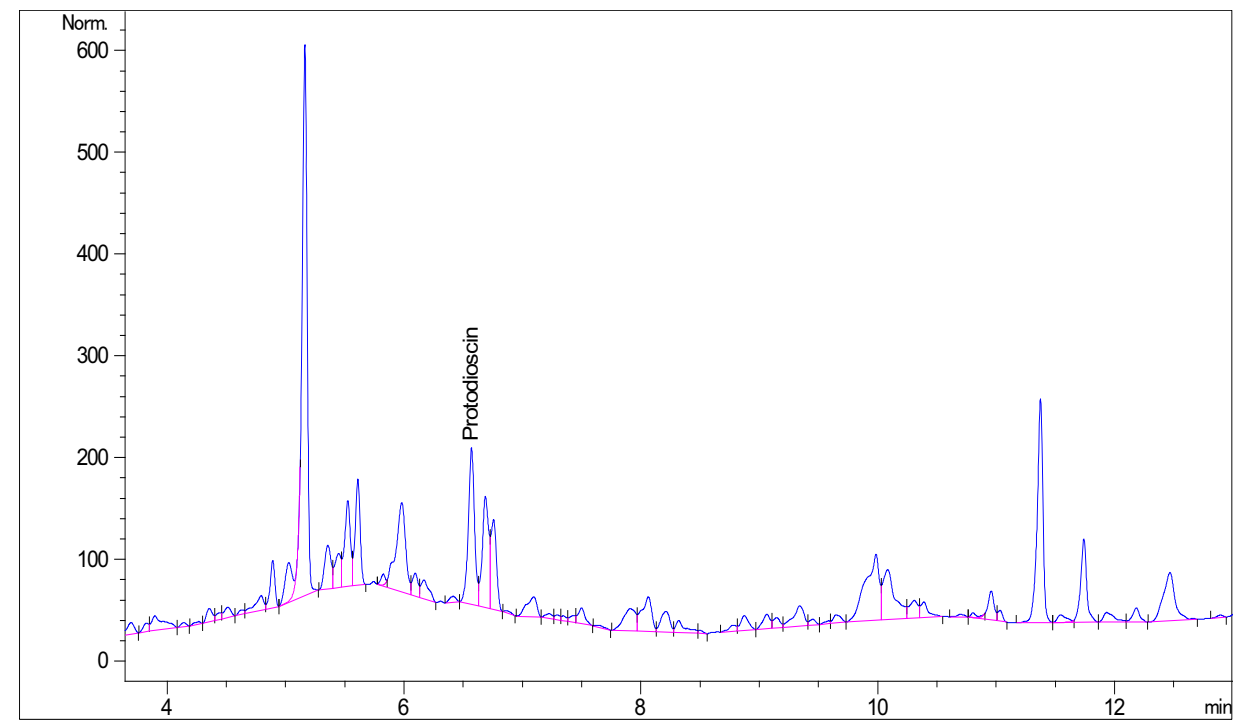

Fig. 4. Chromatogram of Tribulus. terrestris sample (aerial parts from Western Siberia).

Method was used to analyze protodioscin analysis in two plant samples. Protodioscin peak from sample chromatograms was identified with retention time as compared with standard chromatogram. In raw material samples from Crimea was found: $0.546 \% \pm 0.013$ protodioscin and in analyzed material from Western Siberia it was $0.338 \% \pm 0.008$, for $n=3$ (Figure 5).

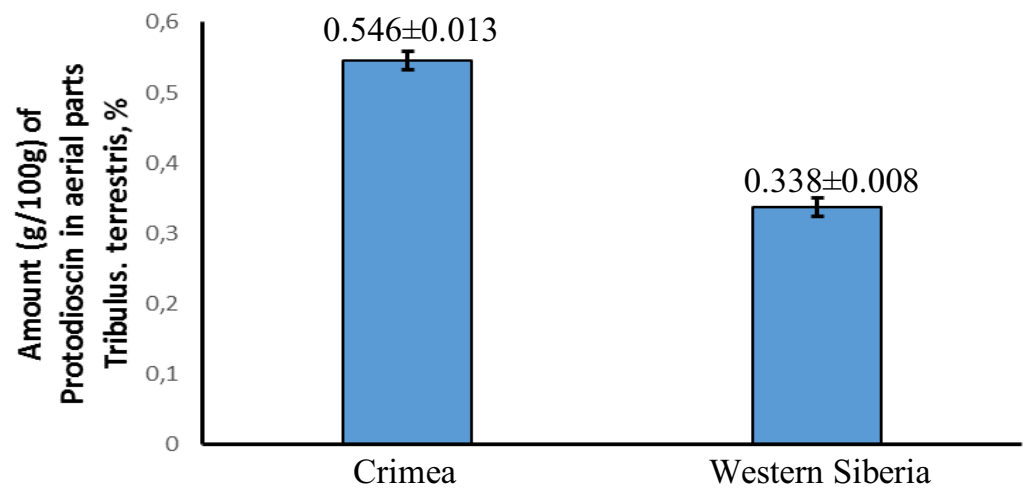

Fig. 5. Amount $(\mathrm{g} / 100 \mathrm{~g})$ of Protodioscin in aerial parts Tribulus. Terrestris.

The data presented in Figure 5 indicate that the raw materials grown on the region of Crimea are promising for the production of phytopreparations. The data obtained are well consistent with those available in the literature $[9,16]$.

\section{Conclusions}

With high performance liquid chromatography protodioscin identification in the raw plants a simple survey has been developed. It allows in 15 minutes determine the protodioscin contents and other steroid compounds in the prepared plant extracts under conditions that they are purchased as standards. 
Protodioscin content in the Tribulus terrestris aerial parts in studied samples growing in the Crimea is on average $60 \%$ higher than in similar raw materials from the West Siberian region. It is possible through favorable agro-climatic conditions on the peninsula. This fact provided an excellent opportunity for biologically active products containing steroid saponins from Crimean raw materials the production.

\section{References}

1. A. Affaf, Yu.N. Karpenko, D.K. Gulyaev et al., Pharmacy \& Pharmacology 7(6), 279290 (2019) doi: 10.19163/2307-9266-2019-7-6-346-355

2. X. Zhang, N. Wei, JU Huang, Y. Tan, D. Jing, Natural Product Resource 80(6), 67-71 (2011) doi:10.1080/14786419.2011.643886

3. G.K. Umarova, Farmatsiya $\quad$ 6, 19-21 https://www.elibrary.ru/item.asp?id=24131184

4. M.N. Samy, M.M. Bishr, A.A. Ahmed et al., Journal of pharmacognosy and phytochemistry zdb 1, 18-22 (2013) https://www.researchgate.net/publication/ 259296512_Pharmacognostical_Studies_on_Flower_of_Tribulus_terrestris_L

5. W. Zhu., Y. Du., H. Meng., Y. Dong., L. Li, Chemistry Central Journal 11, 1-16 (2017) https:// doi 10.1186/s13065-017-0289-x

6. A.M. Dirir, A.J. Cheruth, T. Ksiksi, Journal of Natural Remedies 17(2), 11043 (2017) doi:10.18311/jnr/2017/11043

7. T. Li, Z. Zhang, L. Zhang et al., Journal of Separation Science 32(23-24), 4167-4175 (2009) http://dx.doi.org/10.1002/jssc.200900483

8. O.I. Kozlova, O.I. Perederiaev, G.V. Ramenskaia, Voprosy Pitaniia 80(6), 67-71 (2011) https://www.researchgate.net/publication/223134429_Determination_by_ high_performance_chromatography_steroid_saponins_in_a_biologically_active_food_supplements_containing_the_extract_of_Tribulus_terrestris

9. M. Shishovska, Z. Arsova-Sarafinovska, S. Memeti, Journal of Chemical Engineering Research Updates 2, 12-21 https://www.researchgate.net/publication/275655812_A_Simple_Method_for_Determi nation_of_Protodioscin_in_Tribulus_Terrestris_L_and_Pharmaceuticals_by_HighPerformance_Liquid_Chromatography_Using_Diode-ĀArray_Detection

10. Y. Xu, Y. Liu, T. $\mathrm{Xu}$ et al., Molecules 15, 613-618 (2010) doi:10.3390/molecules15020613

11. C. Saudan, N. Baume, C. Emery, E. Strahm, B. Saugy, Forensic Science International 178(1), 7-10 (2008) http://dx.doi.org/10.1016/j.forsciint.2008.01.003

12. M. Akram, H.M. Asif, N. Akhtar et al., Journal of Medicinal Plant Research 5(16), 3601-3605 (2011) https://www.researchgate.net/publication/260210811_Tribulus_ terrestris_Linn_A_review_article

13. K. Milasius, M. Pečiukonienė, R. Dadeliene, J. Skernevičius, Acta medica Lituanica 17(1), 65-70 (2010) doi:10.2478/v10140-010-0008-6

14. A. Pokrywka, Z. Obmiński, J. Malczewska-Lenczowska, Z. Fijałek, Journal of Human Kinetics 41(1), 99-105 (2014) doi:10.2478/hukin-2014-0037

15. S.G. Angelova, Z. Gospodinova, M. Krasteva, G.G. Antov, J. BioSci. Biotech 2(1), 2532 (2013) https://www.researchgate.net/publication/290890305

16. M. Ganzera, E. Bedir, I.A. Khan, Journal of Pharmaceutical Sciences 90(11), 17521758 (2001) doi: 10.1002/jps. 1124 